\title{
BMP-SMAD1/5 Signaling Regulates Retinal Vascular Development
}

\author{
Andreas Benn ${ }^{1,2}$, Florian Alonso ${ }^{3}{ }^{\circledR}$, Jo Mangelschots ${ }^{1}$, Elisabeth Génot ${ }^{3}$, Marleen Lox $^{1}$ and \\ An Zwijsen 1,*(D) \\ 1 Center for Molecular and Vascular Biology, Department of Cardiovascular Sciences, KU Leuven, \\ 3000 Leuven, Belgium; andreas.benn@gmx.de (A.B.); jomangelschots@hotmail.com (J.M.); \\ Marleen.Lox@kuleuven.be (M.L.) \\ 2 VIB-KU Leuven Center for Brain \& Disease Research, KU Leuven, 3000 Leuven, Belgium \\ 3 Centre de Recherche Cardio-Thoracique de Bordeaux (INSERM U0145), Université de Bordeaux, \\ 33607 Bordeaux, France; f.alonso@iecb.u-bordeaux.fr (F.A.); e.genot@iecb.u-bordeaux.fr (E.G.) \\ * Correspondence: an.zwijsen@kuleuven.be; Tel.: +32-16-33-0006
}

Received: 24 February 2020; Accepted: 18 March 2020; Published: 23 March 2020

\begin{abstract}
Vascular development is an orchestrated process of vessel formation from pre-existing vessels via sprouting and intussusceptive angiogenesis as well as vascular remodeling to generate the mature vasculature. Bone morphogenetic protein (BMP) signaling via intracellular SMAD1 and SMAD5 effectors regulates sprouting angiogenesis in the early mouse embryo, but its role in other processes of vascular development and in other vascular beds remains incompletely understood. Here, we investigate the function of SMAD1/5 during early postnatal retinal vascular development using inducible, endothelium-specific deletion of Smad1 and Smad5. We observe the formation of arterial-venous malformations in areas with high blood flow, and fewer and less functional tip cells at the angiogenic front. The vascular plexus region is remarkably hyperdense and this is associated with reduced vessel regression and aberrant vascular loop formation. Taken together, our results highlight important functions of SMAD1/5 during vessel formation and remodeling in the early postnatal retina.
\end{abstract}

Keywords: arteriovenous malformations; BMP signaling; intussusceptive angiogenesis; retina development; SMAD1/5; sprouting angiogenesis; vessel regression

\section{Introduction}

Bone morphogenetic protein (BMP) signaling is a major regulator of blood vessel formation and maturation. Several studies have demonstrated distinct roles of BMP ligands, receptors, coreceptors and intracellular effectors in many steps of the angiogenic process [1-6]. Likewise, many BMP signaling components, including BMP9, activin-like kinase 1 (ALK1), BMP receptor type II (BMPRII), endoglin (ENG) and common-mediator SMAD4, have been linked - when mutated in their respective encoding genes - to human vascular diseases, including pulmonary arterial hypertension (PAH) and hereditary hemorrhagic telangiectasia (HHT) [3]. Interestingly, however, the principal intracellular effectors of these BMP signaling components, SMAD1 and SMAD5, have so far not been associated with the development of vascular diseases, prompting further investigations into their role in vascular development and function.

We previously demonstrated that a crosstalk between the intracellular BMP effectors SMAD1 and SMAD5 (in here: SMAD1/5) and Notch signaling is required for proper sprouting angiogenesis during mouse embryonic development [7]. After the initial formation of blood vessels via vasculogenesis, vessels form from pre-existing ones via sprouting or intussusceptive angiogenesis. During sprouting 
angiogenesis, tip cells form filopodia and start to migrate in the direction of a growth factor gradient, while trailing stalk cells proliferate and maintain connectivity to the parental vessel. The sprout elongates dynamically and subsequently fuses with another vessel to generate a perfused vessel [8]. During intussusceptive angiogenesis, transluminal pillars are formed by an invagination into the vascular lumen that ultimately splits the parental vessel into two new vessels [9]. Subsequent to the formation of the early network via sprouting and intussusceptive angiogenesis, the vasculature undergoes remodeling processes, such as vessel regression, to generate the mature vasculature [10].

The developing retinal vasculature is a well-acknowledged mammalian model system to study sprouting angiogenesis as it allows visualizing different steps of the angiogenic process simultaneously. The retinal vasculature starts to develop at postnatal $(\mathrm{P})$ day 0 and expands radially from the optic nerve. In the following days, the vasculature expands via sprouting and intussusceptive angiogenesis, and is remodeled into the mature vascular tree [11,12]. In this study, we investigated the effect of inducible, endothelium-specific deletion of Smad1/5 on early postnatal retinal angiogenesis. We show that conditional deletion of $S m a d 1 / 5$ results in direct connections between arteries and veins (arteriovenous malformations, AVMs), fewer and less functional tip cells as well as a hyperdense vascular plexus. We further highlight a role of SMAD1/5 during vessel regression and a potential involvement in intussusceptive angiogenesis. In sum, our data provide a detailed view of the consequences of endothelium SMAD1/5 loss on retinal angiogenesis and vascular remodeling that sheds more light on their function in the endothelium and allows for a direct comparison with other studies performed in the postnatal mouse retina.

\section{Materials and Methods}

\subsection{Animal Experiments}

Homozygous mice for Smad1/Smad5 floxed alleles (Smad1 ${ }^{f l f l} ;$ Smad5 ${ }^{f l f l}$ ) [7] were bred with transgenic mice expressing tamoxifen-inducible Cre in the endothelium (Cdh5-CreERT2tg/0 ) [13]. $S m a d 1^{f l f l} ; S m a d 5^{f l / f l}$ dams were mated with resulting Cdh5-CreERT2 ${ }^{t g / 0} ; S m a d 1^{f l /+} ; S m a d 5^{f l /+}$ mice to obtain Cdh5-CreERT2 ${ }^{\mathrm{tg} / 0}$;Smad ${ }^{f l f l}$;Smad5flfl. Recombination events in the endothelium were visualized using a conditional Cre-reporter strain (RCE) with a CMV-IE enhancer/chicken beta-actin/rabbit beta-globin hybrid promotor (CAG)-boosted expression of enhanced green fluorescent protein (EGFP) in homozygous $R C E^{+/+} ; S m a d 1^{f l f l} ; S m a d 5^{f l f l}$ reporter dams [7]. Pups were injected intraperitoneally with tamoxifen $(500 \mu \mathrm{g})$ at P2 and P3, and sacrificed at P4 or P6. Genotyping of recombined alleles was done as previously described [7]. For perfusion experiments, pups were anesthetized by placing them on ice for $10 \mathrm{~min}$, injected retro-orbitally with fluorescein isothiocyanate FITC-coupled lectin (FL-1171; Vector Laboratories) and lectin was allowed to circulate $5 \mathrm{~min}$ before sacrifice. All experiments were conducted using littermate controls. The Ethical Committee of KU Leuven approval all animal procedures (P039/2017).

\subsection{Reagents and Antibodies}

All reagents and antibodies were purchased from Sigma-Aldrich (Overijse, Belgium), unless stated otherwise.

For immunofluorescence analysis, the following antibodies/reagents were used: biotinylated Griffonia simplicifolia lectin I (isolectin B4) (L2140; 1:40); mouse anti-alpha-smooth muscle actin-Cy3 (C6198; 1:200); goat anti-ephrin type B receptor 4 (E4779; 1:100); rabbit anti-phospho(p)SMAD1/5/9 (\#13820, 1:100, Cell Signaling Technology; Bioké, Leiden, The Netherlands); rabbit anti-erythroblast transformation-specific related gene (ERG, ab110639, 1:200, Abcam, Cambridge, United Kingdom); rabbit anti-collagen IV (ab6586; 1:100, Abcam, Cambridge, United Kingdom); rat anti-endomucin (sc-65495; 1:100; Santa Cruz; Bio-Connect B.V., Huissen, The Netherlands). It is of note that the SMAD8 protein is encoded by the Smad9 gene (which is used in the naming of the \#13820 antibody). Appropriate streptavidin conjugates or species-specific Alexa Fluor-coupled secondary 
antibodies (all 1:200) were purchased from Jackson Immunoresearch (Bio-Connect B.V., Huissen, The Netherlands).

\subsection{Immunofluorescence Analysis and Quantification}

Pups were sacrificed at $\mathrm{P} 4$ or $\mathrm{P} 6$ and whole eyes were isolated and prefixed in $4 \%$ paraformaldehyde (PFA) for $20 \mathrm{~min}$ at room temperature. Subsequently, retinas were dissected, fixed in $4 \%$ PFA for $2 \mathrm{~h}$ at $4{ }^{\circ} \mathrm{C}$ and further processed for immunofluorescence analysis as previously described [14]. For pSMAD1/5/8 staining, retinas were incubated with the primary antibody for $72 \mathrm{~h}$ at $4{ }^{\circ} \mathrm{C}$. Confocal microscopy of flat-mounted retinas was carried out on a Leica SP8 confocal microscope. Analysis and quantification of at least two images per retina were done in a blinded manner using ImageJ (National Institute of Health, Bethesda, Maryland, United States of America). Quantification of pSMAD1/5/8 was performed by manually counting the number of p-SMAD1/5/8 and IB4 double-positive endothelial cells (ECs) per field in the remodeling plexus, and the counts were normalized to the IB4-positive areas quantified using ImageJ software. Radial expansion measurements were performed on IB4-stained flat-mounted retinas by measuring the distance between the optic nerve center and the outmost tip cell. Quantification was done using the mean of eight individual measurements across the flat-mounted retina. Vessel inner diameter was measured on corresponding areas from three distinct points along the same vessel and the resulting means were used for further analysis. Fluorescence intensity was measured by marking a region of interest around individual arteries, veins or AVMs and measuring the signal intensity within the region of interest. Tip cell and filopodia measurements were performed using ERG/IB4 co-stained flat-mounted retinas. Tip cells were defined as the outermost single nuclear cells extending from the angiogenic front. Vascular density was determined on grayscale IB4-stained flat-mounted retinas by measuring the fluorescent area vs. the nonfluorescent area. Empty collagen sleeves and vascular loops were manually counted on Col IV/IB4 co-stained flat-mounted retinas. The mean vascular loop area was quantified on whole optical fields in the plexus region using ImageJ software.

Images were processed and compiled using Adobe Photoshop 2019 (Munich, Germany).

\subsection{Statistical Analysis}

Normal distribution was confirmed using the D'Agostino-Pearson normality test. A Welch's t-test was used to determine statistical significance. $P$-value below 0.05 was considered statistically significant: ${ }^{*} p<0.05 ;{ }^{* *} p<0.01 ;{ }^{* *} p<0.001 ;{ }^{* * *} p<0.0001$. Error bars represent standard deviation. Cre-negative littermates were always used as control group. GraphPad Prism 8.1.1 (San Diego, CA, United States of America) was used for statistical analysis of all quantitative data.

\section{Results}

\subsection{Endothelium-Specific Deletion of Smad1/5 Results in AVM Formation}

We previously showed that a constitutive endothelium-specific double knockout of Smad1/5 is embryonically lethal [7]; therefore, we generated tamoxifen-inducible, endothelium-specific Smad1/5 double knockout mice $\left(\mathrm{dKO}^{\mathrm{iEC}}\right)$ to study their function during postnatal angiogenesis. Mice were treated with tamoxifen at P2 and P3 and subsequently analyzed at P4 or P6 (Figure 1A). Efficient Cre-mediated recombination in endothelial cells (ECs) was visualized using a reporter mouse strain (Figure S1A). Furthermore, we observed significantly fewer ECs with a pSMAD1/5/8 signal in dKO ${ }^{\mathrm{iEC}}$ compared to control mice (Figure S1B,C). Overall, induced deletion of Smad1/5 in the vasculature resulted in premature lethality compared to control mice (Figure 1B) and a 10\% weight loss at P6 (Figure S1D). Therefore, we focused on the role of SMAD1/5 during early retinal vascular development. Injection of fluorescently-labeled lectin showed that retinas were healthy and fully perfused in $\mathrm{dKO} \mathrm{K}^{\mathrm{iEC}}$ at $\mathrm{P6}$ (Figure S1E,F). We observed AVMs at the first branch of major retinal arteries and veins in about 2/3 of $\mathrm{dKO}^{\mathrm{iEC}}$ at P6 (Figure 1C,D). The malformations were already detected at P4, two days after induction 
of recombination, in about $15 \%$ of $\mathrm{dKO}^{\mathrm{iEC}}$ (Figure $\left.\mathrm{S} 2 \mathrm{~A}, \mathrm{~B}\right)$. The majority of $\mathrm{dKO} \mathrm{O}^{\mathrm{iEC}}$ retinas exhibited one AVM and showed an increased inner vein diameter at P6 (Figure 1E,F), while no differences in vessel caliber were observed at P4 (Figure S2C).

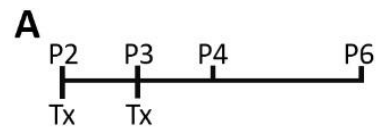

C

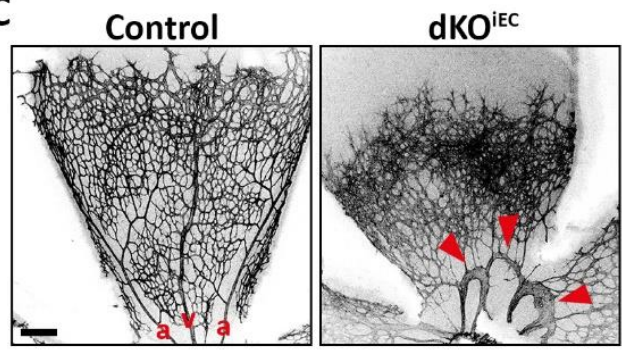

D

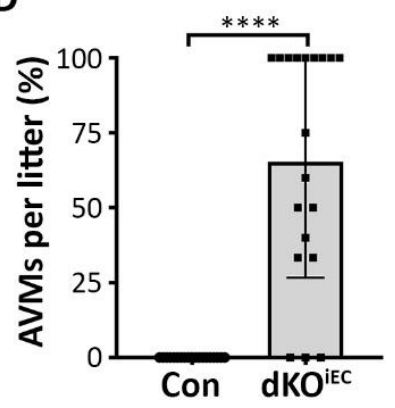

\section{$\mathbf{E}$}

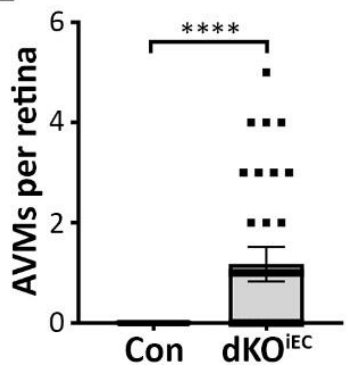

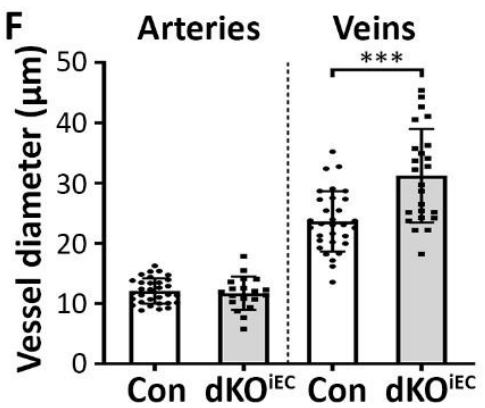

Figure 1. Endothelium-specific Smad1/5 deletion results in arteriovenous malformation (AVM) formation in the retina. (A) Tamoxifen (Tx) treatment regime. Mice were injected with Tx at postnatal day 2 (P2) and P3, and analyzed at P4 or P6. (B) Survival rates of Tx-treated mice. Control $n=18$. dKO $n=15$. (C) Isolectin B4 (IB4) staining of Tx-treated control and double knockout mice $\left(\mathrm{dKO}^{\mathrm{iEC}}\right)$ retinas at P6. Red arrowheads indicate AVMs. a = artery. v = vein. Scale bar: $200 \mu \mathrm{m}$. (D) Quantification of AVMs in Tx-treated litters and (E) number of AVMs per retina at P6. 19 litters with control $n=82$ and $\mathrm{dKO}^{\mathrm{iEC}} n=49$. (F) Quantification of inner vessel diameter of arteries and veins in Tx-treated mice at P6. Control $n=31$. $\mathrm{dKO}^{\mathrm{iEC}} n=19$. ${ }^{* * *} p<0.001$; ${ }^{* * *} p<0.0001$.

Taken together, we show that endothelium-specific deletion of Smad1/5 in postnatal mice results in AVM formation of major retinal arteries and veins.

\subsection{Arterial-and Venous-Associated Markers Localize Normally in $d K O^{i E C}$}

It has been reported that endothelium-specific deletion of Smad4 results in AVM formation and changes in arterial-venous identity in the retina of postnatal mice $[5,15,16]$. Considering the occurrence of AVMs in $\mathrm{dKO}^{\mathrm{iEC}}$ pups, we tested whether changes in the localization of alpha smooth muscle actin $(\alpha$-SMA), a marker of arterial-associated vascular smooth muscle cells (vSMCs), or venous-associated marker ephrin type b receptor 4 (EphB4) would occur in $\mathrm{dKO}^{\mathrm{iEC}}$. About $36 \%(n=4 / 11)$ of all analyzed $\mathrm{dKO}{ }^{\mathrm{iEC}}$ retinas showed no AVM formation and no changes in the exclusive arterial localization of $\alpha$-SMA at P6 (Figure 2A, middle panel). While we observed AVM formation in about $64 \%$ of all analyzed $\mathrm{dKO}{ }^{\mathrm{iEC}}$ retinas $(n=7 / 11)$, only a minor fraction of them $(n=1 / 11)$ demonstrated $\alpha$-SMA localization on an AVM (Figure 2A, right panel). Image quantification showed that $\alpha$-SMA localization remained unaltered between $\mathrm{dKO}{ }^{\mathrm{iEC}}$ mice and control mice, and that $\alpha$-SMA levels in AVMs were mostly below $\alpha$-SMA background level (Figure 2B). Localization of EphB4 was unaffected in $\mathrm{dKO} \mathrm{B}^{\mathrm{iEC}}$ mice showing no AVM formation $(n=3 / 10)$ (Figure $2 C$, middle panel) and was predominantly observed on AVMs $(n=5 / 10)$ (Figure 2C, right panel). The localization of arterial $\alpha$-SMA and venous EphB4 identity markers remained fully intact outside of AVMs (Figure 2D). 
A
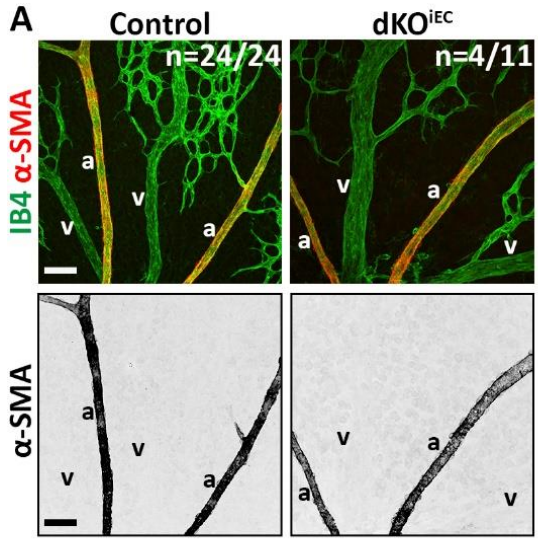

C Control
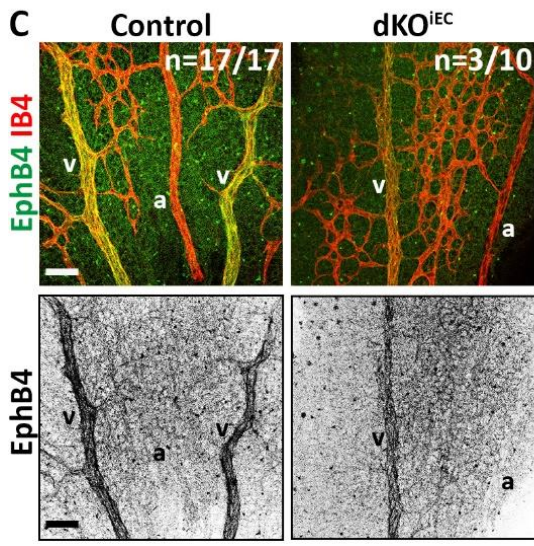

dKO
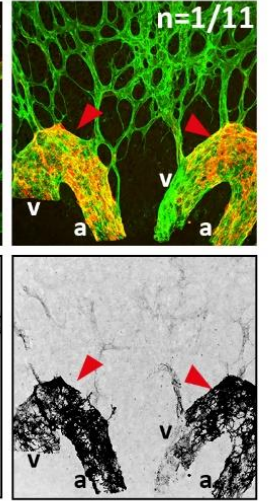

dKO
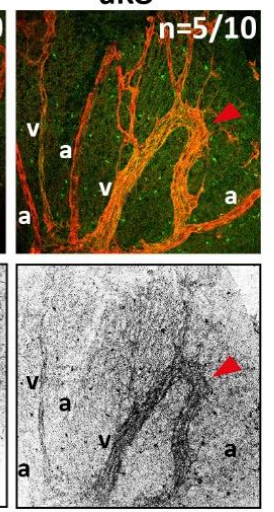

B
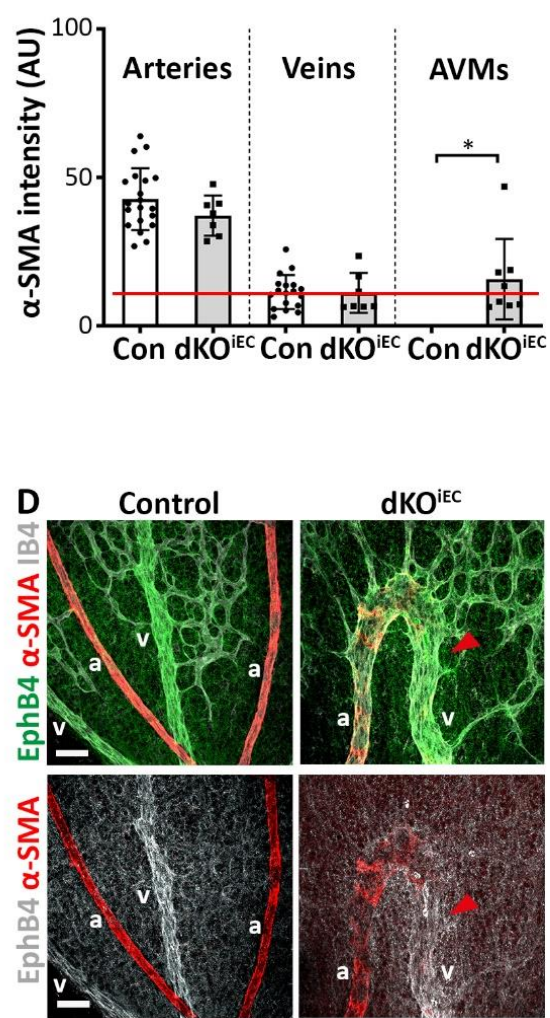

dKO ${ }^{\mathrm{iEC}}$
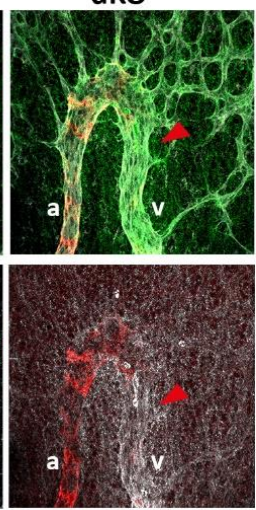

Figure 2. Arterial- and venous-associated markers localize normally in $\mathrm{dKO} \mathrm{iEC}^{\mathrm{iEC}}$ (A) IB4 (green) and alpha smooth muscle actin ( $\alpha$-SMA, red) staining of Tx-treated control $(n=24)$ and dKO ${ }^{\mathrm{iEC}}(n=11 ; 4 / 11$ without AVM formation; 6/11 with $\alpha$-SMA-negative AVMs; $1 / 11$ with $\alpha$-SMA-positive AVM) retinas at P6. $\alpha$-SMA grayscale images are shown for visual clarity. (B) Quantification of $\alpha$-SMA signal intensity per vessel type (arteries, veins, AVMs) in Tx-treated mice at P6. The red line indicates background noise level. (C) Ephrin type b receptor 4 (EphB4, green) and IB4 (red) staining of Tx-treated control $(n=17)$ and $\mathrm{dKO}^{\mathrm{iEC}}(n=10 ; 3 / 10$ without AVM formation; $2 / 10$ with EphB4-negative AVMs; $5 / 10$ with EphB4-positive AVMs) retinas at P6. EphB4 grayscale images are shown for visual clarity. (D) EphB4 (green/white), $\alpha$-SMA (red) and IB4 (white) staining of Tx-treated control and dKO ${ }^{\mathrm{EEC}}$ retinas at P6. Red arrowheads indicate AVMs. $\mathrm{a}=$ artery. $\mathrm{v}=$ vein. Scale bar: $50 \mu \mathrm{m} .{ }^{*} p<0.05$.

Overall, our marker analysis suggests that arterial-venous specification proceeds normally in $\mathrm{dKO}^{\mathrm{iEC}}$ and that AVMs are mainly of venous origin.

\subsection{Endothelial SMAD1/5 Signaling Regulates Tip Cell Formation and Function During Retinal Sprouting Angiogenesis}

Besides the formation of AVMs, we observed a hyperdense vascular network and a reduction in radial outgrowth with $100 \%$ penetrance in the retinal vasculature of $\mathrm{dKO}^{\mathrm{iEC}}$ mice at $\mathrm{P} 6$ compared to control mice (Figure 3A,B). Since radial outgrowth is mainly driven by tip cell migration [17], we analyzed tip cell formation and function. Fewer tip cells and fewer filopodia were observed in $\mathrm{dKO}^{\mathrm{iEC}}$ mice at P6 (Figure 3C-E). At P4, radial outgrowth was not yet significantly affected by the deletion (Figure S2A,D), and tip cell and filopodia numbers were comparable between $\mathrm{dKO}{ }^{\mathrm{iEC}}$ and control mice (Figure S2E,F). Tip cell filopodia sense growth factor gradients and, therefore, typically extend in an angle between $0^{\circ}$ to $60^{\circ}$ relative to the tip cell axis in the direction of the growth factor gradient [17]. We observed a higher percentage of tip cells with filopodial angles $>60^{\circ}$ relative to the tip cell axis in $\mathrm{dKO}^{\mathrm{iEC}}$ mice at $\mathrm{P} 6$ (Figure $3 \mathrm{~F}, \mathrm{G}$ ). These findings reflect disturbed growth factor gradient sensing and/or directed migration of tip cells [18]. 
A

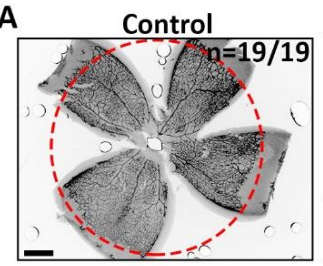

Control

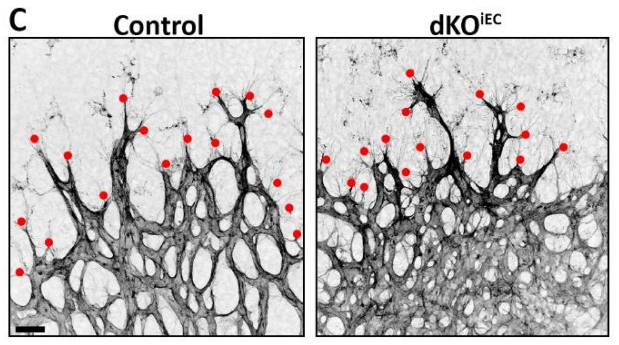

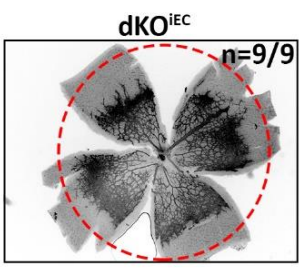

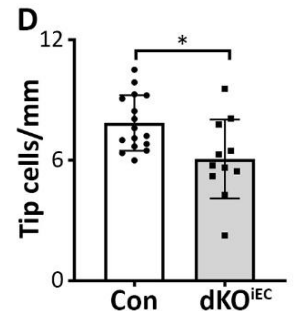

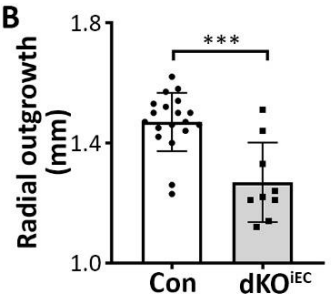
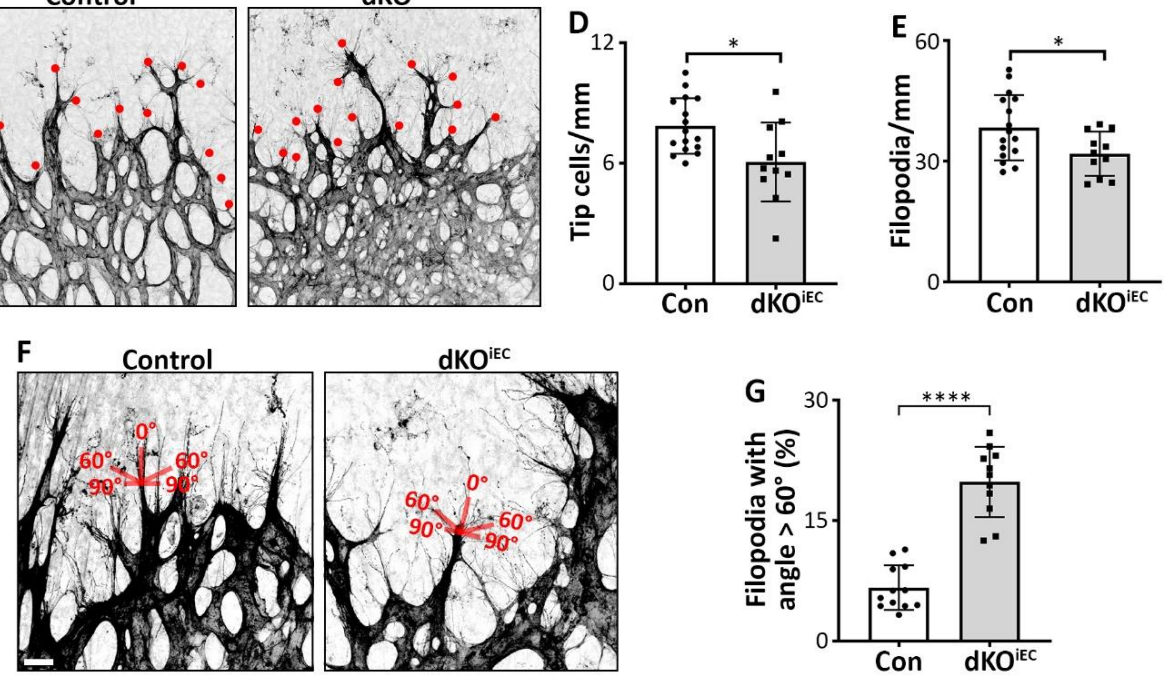

Figure 3. SMAD1/5 signaling regulates tip cell formation and function. (A) IB4 staining of Tx-treated control and $\mathrm{dKO} \mathrm{O}^{\mathrm{iEC}}$ retinas at $\mathrm{P} 6$. The red dotted circle indicates radial outgrowth from control mice. Scale bar: $500 \mu \mathrm{m}$. (B) Quantification of radial outgrowth in Tx-treated mice at P6. Control $n=19$. $\mathrm{dKO}^{\mathrm{iEC}} n=9$. (C) IB4 staining of Tx-treated control and $\mathrm{dKO}{ }^{\mathrm{iEC}}$ retinas at P6. The red dots indicate tip cells. Scale bar: $25 \mu \mathrm{m}$. (D) Quantification of tip cells and (E) tip cell filopodia in Tx-treated mice at P6. Control $n=16$. $\mathrm{dKO}{ }^{\mathrm{iEC}} n=11$. (F) IB4 staining of Tx-treated control and dKO ${ }^{\mathrm{iEC}}$ at P6. The scheme represents the angle of filopodia from respective tip cells. Scale bar: $10 \mu \mathrm{m}$. (G) Quantification of filopodia with an angle $>60^{\circ}$ respective to their tip cell in Tx-treated mice at P6. Control $n=12$. dKO $n=11 .{ }^{*} p<0.05 ; * * * p<0.001 ; * * * * 00.0001$.

In sum, we report that Smad1/5-deficient ECs have fewer, less functional tip cells and show signs of migration defects.

\subsection{KKO ${ }^{i E C}$ Mice Show Reduced Vessel Regression and Increased Vascular Loop Formation}

Since we observed distinct effects in distinct regions of the retinal vascular network in $\mathrm{dKO} \mathrm{iEC}^{\mathrm{EC}}$ mice (Figure 3A), we segmented the retinal vasculature in three distinct regions that would allow for appropriate comparison with control mice: (i) the frontal region with migrating tip cells; (ii) the intermediate remodeling plexus region; and (iii) the mature core region around the optic nerve (Figure 4A). Vascular density was increased significantly in the plexus region of $\mathrm{dKO}^{\mathrm{iEC}}$ mice at P6 (Figure 4B), while the density was increased in the frontal region at $\mathrm{P} 4$ compared to control mice (Figure S3A,B). Analysis of the endothelium-specific transcription factor ERG [14] demonstrated that total EC numbers were unaffected in $\mathrm{dKO} \mathrm{i}^{\mathrm{iEC}}$ mice (Figure $4 \mathrm{C}$ ), suggesting that a change in cell number did not contribute to the hyperdense plexus. We therefore hypothesized that vessel regression and/or intussusceptive angiogenesis could be deregulated in $\mathrm{dKO}^{\mathrm{iEC}}$ mice. Vessel regression helps in establishing the mature vascular tree [10]. We observed fewer empty collagen IV sleeves in the plexus region of $\mathrm{dKO}{ }^{\mathrm{iEC}}$ mice at $\mathrm{P} 6$ (Figure $4 \mathrm{D}, \mathrm{E}$ ), indicating disturbed vessel regression. During blood vessel formation, sprouting and intussusceptive angiogenesis often occur in parallel, with sprouting angiogenesis contributing to the initial network, while remodeling vessels undergo intussusceptive angiogenesis to establish mature retinal vascular networks [12]. Retinal vascular loop formation has 
been associated with intussusceptive angiogenesis [19]. We observed significantly more vascular loops in $\mathrm{dKO}^{\mathrm{iEC}}$ mice compared to control mice at P6 (Figure 4D,F). Loop area was significantly reduced upon the deletion of Smad1/5 in ECs (Figure 4D,G).

A
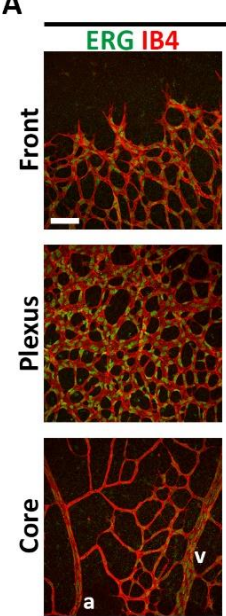

B

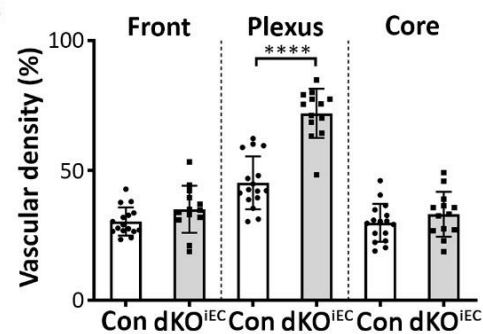

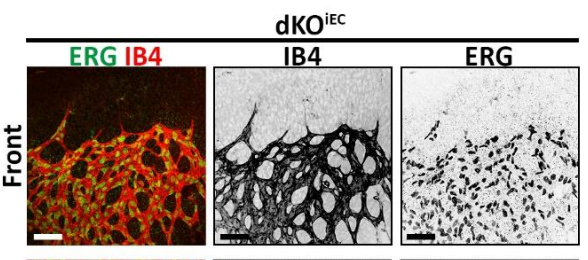
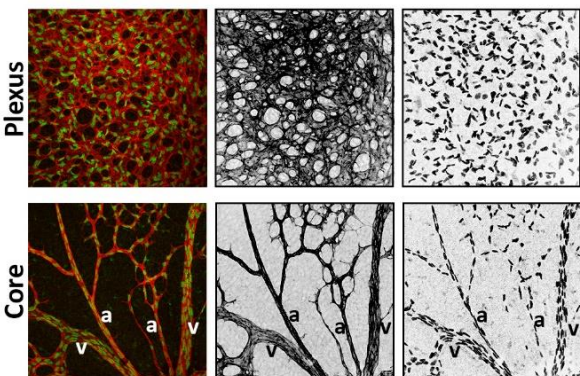

C

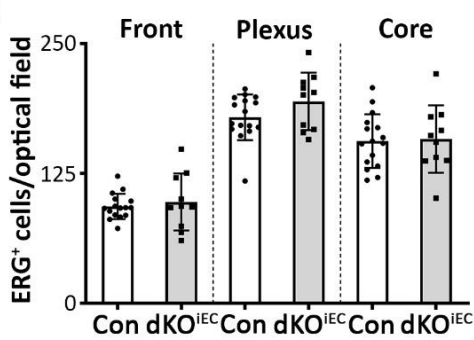

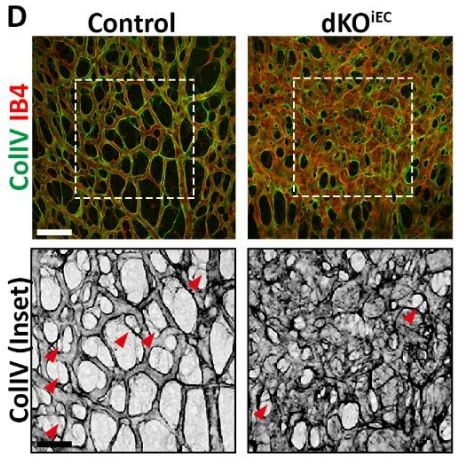
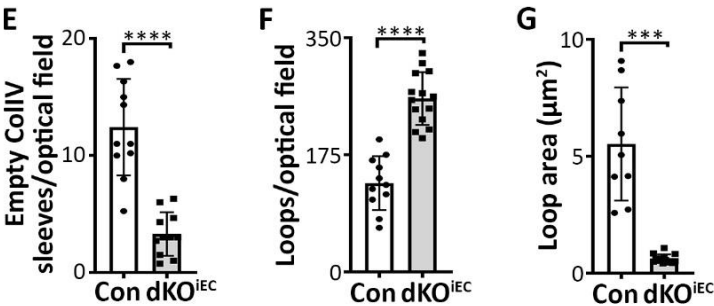

Figure 4. $\mathrm{dKO}{ }^{\mathrm{iEC}}$ mice show increased vascular density, reduced vessel regression and more abundant loop formation in the retinal plexus region. (A) ERG (green) and IB4 (red) staining of Tx-treated control and $\mathrm{dKO}^{\mathrm{iEC}}$ retinas at P6. Retinal leaflets have been divided into three distinct regions: (i) the frontal region with migrating tip cells; (ii) the intermediate remodeling plexus region; and (iii) the mature core region around the optic nerve. Grayscale images of IB4 and ERG staining are shown for visual clarity. a = artery. $\mathrm{v}=$ vein. Scale bar: $50 \mu \mathrm{m}$. (B) Quantification of vascular density at the retinal vascular frontal, plexus and core regions of Tx-treated mice at P6. Control $n=16$. $\mathrm{dKO}^{\mathrm{iEC}} n=13$. (C) Quantification of ERG ${ }^{+}$ECs at the retinal vascular frontal, plexus and core regions of Tx-treated mice at P6. Control $n=16$. $\mathrm{dKO} \mathrm{E}^{\mathrm{iEC}} n=10$. (D) Collagen IV (ColIV, green) and IB4 (red) staining of Tx-treated control and $\mathrm{dKO}^{\mathrm{iEC}}$ retinas at P6. ColIV grayscale images are shown for visual clarity. White dotted box highlights enlarged inset. Red arrows indicate empty ColIV sleeves. Scale bars: $50 \mu \mathrm{m}$ (upper panel) and $25 \mu \mathrm{m}$ (inset). (E) Quantification of empty ColIV sleeves in the retinal plexus region of Tx-treated mice at P6. Control $n=11$. $\mathrm{dKO}^{\mathrm{iEC}}=11$. $(\mathbf{F}, \mathbf{G})$ Quantification of the number of vascular loops and the mean vascular loop area in the retinal plexus region of Tx-treated mice at P6. Control $n=11 . \mathrm{dKO}{ }^{\mathrm{iEC}}=14 .{ }^{* * *} p<0.001 ;{ }^{* * * *} p<0.0001$. 
Our data demonstrate that endothelium-specific deletion of Smad1/5 results in a hyperdense vascular plexus network, due to decreased vessel regression and potentially increased intussusceptive angiogenesis during postnatal retinal vascular development.

\section{Discussion}

Our study highlights endothelial SMAD1/5 as regulators of distinct blood vessel formation phases in the early postnatal mouse retina and their deletion results in massive vascular defects. The presence of AVMs of the first branch point of arteries or veins in about two thirds of the retinas of $\mathrm{dKO} \mathrm{iEC}^{\mathrm{iEC}}$ mice, suggested that AVM formation is not a fully penetrant phenotype in our model. Presence of AVM-like malformations were also found in embryos with an endothelium-specific deletion of Smad1/5 [20]. To some extent, the retinal AVMs described here resemble the previously described AVMs of endothelium-specific Smad4 knockout mice (Smad4 ${ }^{i E C}$ ) [5]. Although AVMs in $S m a d 4^{i E C}$ mice were also formed in regions with high blood flow, the authors also report changes in the arterial-venous identity, specifically increased venous $\alpha$-SMA coverage and arterial presence of the venous marker EphB4 in Smad4 ${ }^{i E C}$ mice. While AVMs are mostly of venous origin, we did not observe changes in the localization of arterial- and venous-associated markers in $\mathrm{dKO}^{\mathrm{iEC}}$ mice. We also did not observe changes in the venous-exclusive presence of EphB4, suggesting that venous identity and EphB4 localization are unaffected by endothelium-specific deletion of Smad1/5. This finding is in contrast to a previous study describing a SMAD1/5 binding motif in an enhancer region of EphB4 and a BMP-ALK3-SMAD1/5-dependent control of venous identity in mouse embryos and zebrafish [21]. We speculate that the observed differences in $\mathrm{dKO}^{\mathrm{iEC}}$ mice compared to endothelium-specific deletion of Alk1, Smad4 [5], Alk3 [21] or Eng [3] are due to mechanistic differences in the resulting BMP-SMAD signal transduction in the respective mutants. Considering the role of these BMP signaling components in the pathogenesis of diseases such as HHT [2,3,5,22], an understanding of the underlying molecular mechanisms is paramount to the identification of novel therapeutic targets.

We also observed significantly reduced radial outgrowth, less functional tip cells and an increased density of the plexus region with full penetrance in all $\mathrm{dKO}^{\mathrm{iEC}}$ mice during postnatal retinal angiogenesis. We previously showed that endothelium-specific deletion of Smad1/5 results in more tip cell-like cells in the mouse hindbrain region at E9.5 due to a crosstalk between SMAD1/5 and Notch-dependent signaling [7]. While this seems to contradict our current data, results presented in this study are in line with a set of endothelium-specific BMP receptor knockouts in the early postnatal mouse retina. It has been reported that endothelium-specific knockouts of the BMP receptors $A l k 1\left(A l k 1^{i E C}\right), A l k 2\left(A l k 2^{i E C}\right)$, $A l k 3\left(A l k 3^{i E C}\right)$ and Bmpr2 (Bmpr $\left.2^{i E C}\right)$ have very distinct outcomes on radial expansion of the retinal vasculature, tip cell formation and vascular density in transgenic mice at P5. While $A l k 1^{i E C}$ mice exhibit no changes in radial outgrowth, but an increased number in tip cells and a higher vascular density [4,6], $A l k 2^{i E C}, A l k 3^{i E C}$ and $B m p r 2^{i E C}$ mice demonstrate reduced radial outgrowth, tip cell number and vascular density [4]. Based on these findings, we speculate that tip cell formation and function are predominantly regulated by ALK2, ALK3 or BMPRII in a SMAD1/5-dependent manner in the early postnatal mouse retina. We hypothesize that loss of SMAD1/5 shifts endothelial BMP signaling towards SMAD2/3 signaling that has been shown to regulate vascular stability [23] and stalk cell competence [1], and can be activated by BMP receptors [24]. This shift could cause an imbalance in tip and stalk cell formation as observed here and elsewhere $[4,6,7,18]$. These findings also highlight the delicate relationship between the involved BMP receptors and coreceptors, their resulting heteromeric complexes, the activated downstream effectors and the resulting outcomes on sprouting angiogenesis. We previously identified that distinct BMP signaling modes depend on BMP receptor expression, which in turn is dependent on the vascular bed [25]. Thus, a differential expression of BMP signaling components likely explains the observed differences between endothelium-specific deletion of Smad1/5 in different vascular beds.

Finally, we observed an increased vascular density in the plexus region of $\mathrm{dKO}^{\mathrm{iEC}}$ mice. Considering the striking morphology of the dense plexus, we speculated that this hyperdensity 
could result from either a change in total EC numbers or EC size, vessel regression or intussusceptive angiogenesis. While EC numbers were comparable between $\mathrm{dKO}^{\mathrm{iEC}}$ and control mice, we observed fewer empty collagen IV sleeves and more vascular loops that were indicative of reduced vessel regression and intussusceptive angiogenesis, respectively, in the plexus region. Although both mechanisms regulate vascular maturation, in-depth molecular details remain incompletely understood. Vessel regression, EC migration and intussusceptive angiogenesis are driven by blood flow but they respond to distinct blood flow profiles $[10,12,26]$. We observed significant hyperdensity in the plexus region, which is exposed to lower blood flow compared to the core region around the optic nerve [27]. Since BMP-SMAD1/5 signaling has repeatedly been shown to be sensitive to shear stress [27-30], we assume that SMAD1/5-dependent signaling controls vessel regression and intussusceptive angiogenesis in a blood flow-dependent manner.

Our study provides an insight into the role of SMAD1/5 during blood vessel formation in the postnatal mouse retina. We show that in $\mathrm{dKO} \mathrm{iEC}^{\mathrm{iE}}$ mice, AVMs form in areas of high blood flow, while reduced vessel regression and increased loop formation can occur in areas of lower blood flow. Besides, deletion of Smad1/5 results in fewer and less functional tip cells. Collectively, these data highlight distinct roles of SMAD1/5-dependent signaling in the orchestrated process of blood vessel formation, ranging from tip cell migration to vessel remodeling. Future studies should address the specific molecular mechanisms of SMAD1/5-dependent signaling during distinct vascular development processes. Understanding these processes may lead to the identification of novel therapeutic targets for BMP-SMAD1/5-dependent vascular diseases, such as HHT.

Supplementary Materials: The following are available online at http://www.mdpi.com/2218-273X/10/3/488/s1, Figure S1: Efficient recombination and perfusion in Tamoxifen-treated endothelial-specific Smad1/5 knockout mice at P6; Figure S2: Early postnatal stage deletion of Smad1/5 in endothelial cells results induces vascular malformations at P4; Figure S3: dKOiEC mice show increased vascular density in the front region at P4.

Author Contributions: A.B. and A.Z. conceived the study and designed the experiments; A.B., J.M., F.A. and M.L. performed the experiments and analyzed the data together with E.G. and A.Z.; A.B. and A.Z. wrote the manuscript. All authors have read and agreed to the published version of the manuscript.

Funding: This research was funded by the Deutsche Forschungsgemeinschaft with a fellowship in support of A.B. [BE 6338/1-1). F.A is supported by a fellowship from Fondation Berthe Fouassier/Fondation de France. This work is supported by grants from the KU Leuven (C12/16/023, C14/19/095) and the VIB Center for Brain and Disease Research.

Acknowledgments: We thank J. Ksiazkiewicz and M. B. Veiga for ImageJ support, E. Maas and R. Vandepoel for mouse husbandry, and A. Luttun, F. Itoh, M. Staring, L. Ponomarev and N. Criem for interesting discussions.

Conflicts of Interest: The authors declare no conflicts of interest.

\section{References}

1. Aspalter, I.M.; Gordon, E.; Dubrac, A.; Ragab, A.; Narloch, J.; Vizan, P.; Geudens, I.; Collins, R.T.; Franco, C.A.; Abrahams, C.L.; et al. Alk1 and Alk5 inhibition by Nrp1 controls vascular sprouting downstream of Notch. Nat. Commun. 2015, 6, 7264. [CrossRef] [PubMed]

2. Garcia de Vinuesa, A.; Abdelilah-Seyfried, S.; Knaus, P.; Zwijsen, A.; Bailly, S. BMP signaling in vascular biology and dysfunction. Cytokine Growth Factor Rev. 2016, 27, 65-79. [CrossRef] [PubMed]

3. Jin, Y.; Muhl, L.; Burmakin, M.; Wang, Y.; Duchez, A.C.; Betsholtz, C.; Arthur, H.M.; Jakobsson, L. Endoglin prevents vascular malformation by regulating flow-induced cell migration and specification through VEGFR2 signalling. Nat. Cell. Biol. 2017, 19, 639-652. [CrossRef] [PubMed]

4. Lee, H.W.; Chong, D.C.; Ola, R.; Dunworth, W.P.; Meadows, S.; Ka, J.; Kaartinen, V.M.; Qyang, Y.; Cleaver, O.; Bautch, V.L.; et al. Alk2/ACVR1 and Alk3/BMPR1A Provide Essential Function for Bone Morphogenetic Protein-Induced Retinal Angiogenesis. Arter. Thromb. Vasc. Biol. 2017, 37, 657-663. [CrossRef] [PubMed]

5. Ola, R.; Kunzel, S.H.; Zhang, F.; Genet, G.; Chakraborty, R.; Pibouin-Fragner, L.; Martin, K.; Sessa, W.; Dubrac, A.; Eichmann, A. SMAD4 Prevents Flow Induced Arteriovenous Malformations by Inhibiting Casein Kinase 2. Circulation 2018, 138, 2379-2394. [CrossRef] [PubMed] 
6. Tual-Chalot, S.; Mahmoud, M.; Allinson, K.R.; Redgrave, R.E.; Zhai, Z.; Oh, S.P.; Fruttiger, M.; Arthur, H.M. Endothelial depletion of Acvrl1 in mice leads to arteriovenous malformations associated with reduced endoglin expression. PLOS ONE 2014, 9, e98646. [CrossRef]

7. Moya, I.M.; Umans, L.; Maas, E.; Pereira, P.N.; Beets, K.; Francis, A.; Sents, W.; Robertson, E.J.; Mummery, C.L.; Huylebroeck, D.; et al. Stalk cell phenotype depends on integration of Notch and Smad1/5 signaling cascades. Dev. Cell. 2012, 22, 501-514. [CrossRef]

8. Carmeliet, P.; Jain, R.K. Molecular mechanisms and clinical applications of angiogenesis. Nature 2011, 473, 298-307. [CrossRef]

9. Mentzer, S.J.; Konerding, M.A. Intussusceptive angiogenesis: Expansion and remodeling of microvascular networks. Angiogenesis 2014, 17, 499-509. [CrossRef]

10. Korn, C.; Augustin, H.G. Mechanisms of Vessel Pruning and Regression. Dev. Cell. 2015, 34, 5-17. [CrossRef]

11. Stahl, A.; Connor, K.M.; Sapieha, P.; Chen, J.; Dennison, R.J.; Krah, N.M.; Seaward, M.R.; Willett, K.L.; Aderman, C.M.; Guerin, K.I.; et al. The mouse retina as an angiogenesis model. Invest. Ophthalmol. Vis. Sci. 2010, 51, 2813-2826. [CrossRef] [PubMed]

12. De Spiegelaere, W.; Casteleyn, C.; Van den Broeck, W.; Plendl, J.; Bahramsoltani, M.; Simoens, P.; Djonov, V.; Cornillie, P. Intussusceptive angiogenesis: A biologically relevant form of angiogenesis. J. Vasc. Res. 2012, 49, 390-404. [CrossRef] [PubMed]

13. Sorensen, I.; Adams, R.H.; Gossler, A. DLL1-mediated Notch activation regulates endothelial identity in mouse fetal arteries. Blood 2009, 113, 5680-5688. [CrossRef] [PubMed]

14. Shah, A.V.; Birdsey, G.M.; Peghaire, C.; Pitulescu, M.E.; Dufton, N.P.; Yang, Y.; Weinberg, I.; Osuna Almagro, L.; Payne, L.; Mason, J.C.; et al. The endothelial transcription factor ERG mediates Angiopoietin-1-dependent control of Notch signalling and vascular stability. Nat. Commun. 2017, 8, 16002. [CrossRef] [PubMed]

15. Crist, A.M.; Lee, A.R.; Patel, N.R.; Westhoff, D.E.; Meadows, S.M. Vascular deficiency of Smad4 causes arteriovenous malformations: A mouse model of Hereditary Hemorrhagic Telangiectasia. Angiogenesis 2018, 21, 363-380. [CrossRef]

16. Kim, Y.H.; Choe, S.W.; Chae, M.Y.; Hong, S.; Oh, S.P. SMAD4 Deficiency Leads to Development of Arteriovenous Malformations in Neonatal and Adult Mice. J. Am. Heart Assoc. 2018, 7, e009514. [CrossRef]

17. Gerhardt, H.; Golding, M.; Fruttiger, M.; Ruhrberg, C.; Lundkvist, A.; Abramsson, A.; Jeltsch, M.; Mitchell, C.; Alitalo, K.; Shima, D.; et al. VEGF guides angiogenic sprouting utilizing endothelial tip cell filopodia. J. Cell Biol. 2003, 161, 1163-1177. [CrossRef]

18. Thalgott, J.H.; Dos-Santos-Luis, D.; Hosman, A.E.; Martin, S.; Lamande, N.; Bracquart, D.; Srun, S.; Galaris, G.; de Boer, H.C.; Tual-Chalot, S.; et al. Decreased Expression of Vascular Endothelial Growth Factor Receptor 1 Contributes to the Pathogenesis of Hereditary Hemorrhagic Telangiectasia Type 2. Circulation 2018, 138, 2698-2712. [CrossRef]

19. Taylor, A.C.; Seltz, L.M.; Yates, P.A.; Peirce, S.M. Chronic whole-body hypoxia induces intussusceptive angiogenesis and microvascular remodeling in the mouse retina. Microvasc. Res. 2010, 79, 93-101. [CrossRef]

20. Peacock, H.M.; Tabibian, A.; Criem, N.; Caolo, V.; Hamard, L.; Deryckere, A.; Haefliger, J.A.; Kwak, B.R.; Zwijsen, A.; Jones, E.A.V. Impaired SMAD1/5 Mechanotransduction and Cx37 (Connexin37) Expression Enable Pathological Vessel Enlargement and Shunting. Arter. Thromb. Vasc. Biol. 2020. [CrossRef]

21. Neal, A.; Nornes, S.; Payne, S.; Wallace, M.D.; Fritzsche, M.; Louphrasitthiphol, P.; Wilkinson, R.N.; Chouliaras, K.M.; Liu, K.; Plant, K.; et al. Venous identity requires BMP signalling through ALK3. Nat. Commun. 2019, 10, 453. [CrossRef] [PubMed]

22. Tual-Chalot, S.; Oh, S.P.; Arthur, H.M. Mouse models of hereditary hemorrhagic telangiectasia: Recent advances and future challenges. Front. Genet. 2015, 6, 25. [CrossRef] [PubMed]

23. Itoh, F.; Itoh, S.; Adachi, T.; Ichikawa, K.; Matsumura, Y.; Takagi, T.; Festing, M.; Watanabe, T.; Weinstein, M.; Karlsson, S.; et al. Smad2/Smad3 in endothelium is indispensable for vascular stability via S1PR1 and $\mathrm{N}$-cadherin expressions. Blood 2012, 119, 5320-5328. [CrossRef] [PubMed]

24. Holtzhausen, A.; Golzio, C.; How, T.; Lee, Y.H.; Schiemann, W.P.; Katsanis, N.; Blobe, G.C. Novel bone morphogenetic protein signaling through $S \operatorname{mad} 2$ and Smad3 to regulate cancer progression and development. Faseb. J. 2014, 28, 1248-1267. [CrossRef]

25. Benn, A.; Hiepen, C.; Osterland, M.; Schutte, C.; Zwijsen, A.; Knaus, P. Role of bone morphogenetic proteins in sprouting angiogenesis: Differential BMP receptor-dependent signaling pathways balance stalk vs. tip cell competence. Faseb J. 2017, 31, 4720-4733. [CrossRef] 
26. Franco, C.A.; Jones, M.L.; Bernabeu, M.O.; Geudens, I.; Mathivet, T.; Rosa, A.; Lopes, F.M.; Lima, A.P.; Ragab, A.; Collins, R.T.; et al. Dynamic endothelial cell rearrangements drive developmental vessel regression. PloS Biol. 2015, 13, e1002125. [CrossRef]

27. Baeyens, N.; Larrivee, B.; Ola, R.; Hayward-Piatkowskyi, B.; Dubrac, A.; Huang, B.; Ross, T.D.; Coon, B.G.; Min, E.; Tsarfati, M.; et al. Defective fluid shear stress mechanotransduction mediates hereditary hemorrhagic telangiectasia. J. Cell Biol. 2016, 214, 807-816. [CrossRef]

28. Vion, A.C.; Alt, S.; Klaus-Bergmann, A.; Szymborska, A.; Zheng, T.; Perovic, T.; Hammoutene, A.; Oliveira, M.B.; Bartels-Klein, E.; Hollfinger, I.; et al. Primary cilia sensitize endothelial cells to BMP and prevent excessive vascular regression. J. Cell Biol. 2018, 217, 1651-1665. [CrossRef]

29. Zhou, J.; Lee, P.L.; Lee, C.I.; Wei, S.Y.; Lim, S.H.; Lin, T.E.; Chien, S.; Chiu, J.J. BMP receptor-integrin interaction mediates responses of vascular endothelial Smad1/5 and proliferation to disturbed flow. J. Thromb. Haemost. 2013, 11, 741-755. [CrossRef]

30. Zhou, J.; Lee, P.L.; Tsai, C.S.; Lee, C.I.; Yang, T.L.; Chuang, H.S.; Lin, W.W.; Lin, T.E.; Lim, S.H.; Wei, S.Y.; et al. Force-specific activation of Smad1/5 regulates vascular endothelial cell cycle progression in response to disturbed flow. Proc. Natl. Acad. Sci. USA 2012, 109, 7770-7775. [CrossRef]

(C) 2020 by the authors. Licensee MDPI, Basel, Switzerland. This article is an open access article distributed under the terms and conditions of the Creative Commons Attribution (CC BY) license (http://creativecommons.org/licenses/by/4.0/). 